\title{
Effects of lubrication on air-sealing performance of a pediatric cuffed tracheal tube
}

\author{
Hiroko Nishioka', Yutaka Usuda², Go Hirabayashi ${ }^{1}$, Koichi Maruyama ${ }^{1}$ and Tomio Andoh ${ }^{1 *}$ (D)
}

\begin{abstract}
Background: Lubrication of cuffed tracheal tubes (CTTs) reduces liquid leakage. However, it is not clear how cuff lubrication influences air leakage. We aimed to test the hypothesis that pretreatment with K-Y jelly, a water-soluble lubricant, would improve the air-sealing performance of pediatric CTTs in a model study.

Methods: We placed Parker Flex-Tip ${ }^{\mathrm{TM}} \mathrm{CTT}$ with 4.0- and 5.0-mm internal diameter (ID) into a tracheal model with 9and 12-mm ID. The tracheal model was connected to a test lung ventilated in pressure control mode. We compared three cuff lubrication conditions: none (N), water (W), and K-Y jelly (KY). We measured the leak airway pressure (LAWP), defined as the lowest peak airway pressure (PAWP) at which leakage was detected, with the fixed cuff pressure (CP) at $20 \mathrm{cmH}_{2} \mathrm{O}$ and varied PAWP. We also measured the leak CP (LCP), defined as the highest CP at which leakage was detected, with fixed PAWP at $25 \mathrm{cmH}_{2} \mathrm{O}$ and varied CP. We confirmed air leakage when an apparent elevation of oxygen concentration was detected above the cuff after changing the inspiratory gas from air to oxygen.
\end{abstract}

Results: For both 4.0-mm ID and 5.0-mm ID endotracheal tubes, the KY group showed significantly higher LAWP and lower LCP than the other two groups. For the 4.0-mm ID, median values and ranges of LAWP and LCP were K-Y group: 25 (25) and 15 (15); N group: 5 (5) and 35 (35): and W group: 5 (5) and 35 (15-35) $\mathrm{CmH}_{2} \mathrm{O}$. For the 5.0-mm ID, median values and ranges of LAWP and LCP were K-Y group: 25 (15-25) and 15 (15-35); N group: 5 (5) and 35 (35); and W group: 5 (5) and $35(15-35) \mathrm{cmH}_{2} \mathrm{O}$. Water application did not change these outcomes compared with the $\mathrm{N}$ group.

Conclusion: Pre-treatment of the cuff with K-Y jelly significantly improved the air-sealing performance of a pediatric $\mathrm{CTT}$ in our model study.

Keywords: Air leakage, K-Y jelly, Tracheal tube

\section{Background}

It is well known that the materials and shapes of endotracheal tube cuffs influence their air-sealing properties. $[1,2]$ For example, Microcuff pediatric tracheal tubes have been shown to exhibit better air-sealing performance than conventional cuffs. [1] It is also known that lubrication of cuffed tracheal tubes reduces liquid leakage in adult cuffed tubes in a bench-top study and clinical studies. [3-5] However, it is not clear how pretreatment of the cuff with lubricants influences air leakage. It is likely that longitudinal folds formed on the cuff

\footnotetext{
*Correspondence: psdelico06@yahoo.co.jps

'Department of Anesthesiology, Mizonokuchi Hospital, Teikyo University

School of Medicine, 3-8-3 Mizonokuchi, Takatsu-ku, Kawasaki 213-8507, Japan

Full list of author information is available at the end of the article
}

wall serve as channels for both air and liquid to pass through and that lubrication may fill these channels and similarly reduce both liquid and air leakage. [6] However, there is a large difference in viscosity between air and liquid. The viscosity of oxygen is approximately 500 times lower than that of airway secretions. [7, 8] In addition, the pressure gradients across the channels are different for the two types of leakage. [9, 10] Fluid leakage seemed to be regulated by the pressure difference between the hydrostatic pressure of fluid accumulated on the cuff and the end-expiratory airway pressure, [10] whereas air leakage may be influenced by the peak airway pressure (PAWP). [9] These physical and rheological factors would greatly influence the nature and magnitude of the leakage. If we assume that leakage has 
properties of laminal flow, the leak flow would be correlated with the pressure gradient and inversely correlated with viscosity. [11] Using a tracheal model, we aimed to test the hypothesis that pretreatment with K-Y jelly, a water soluble lubricant, would improve the air-sealing performance of pediatric cuffed tracheal tubes.

\section{Methods}

We placed Parker Flex-Tip ${ }^{\text {tw }}$ tracheal tubes of the highvolume low-pressure cuffed type with an internal diameter (ID) of $5.0 \mathrm{~mm}$ (Parker tube; Parker Medical, Highlands Ranch, CO, USA, International product number: I-PFHV-50) into a tracheal model consisting of an acrylic cylinder with ID of $12 \mathrm{~mm}$ to simulate an approximately 8-year-old patient. [12, 13] We also used Parker Flex-Tip ${ }^{\text {ta }}$ tracheal tubes of the preformed oral cuffed type with ID of $4.0 \mathrm{~mm}$ (International product number: I-PFOC-40) and an acrylic tracheal model with ID of $9 \mathrm{~mm}$ to simulate an approximately 4-year-old patient. The cuffs of the both tracheal tubes are made of polyvinyl chloride (PVC) and have similar cylindrical shapes. We chose Parker Flex-Tip ${ }^{\text {Tw }}$ tracheal tubes as representative examples of tubes with cylindrical shaped PVC cuffs. The tracheal model was connected to a test lung, and the tracheal tube was connected to an Avance Carestation (GE HealthCare, Fairfield, CT, USA) through a respiratory circuit. The test lung was ventilated with the pressure control mode at an inspiratory to expiratory time ratio of 1:2 and frequency of 15 breaths/min. We compared three lubrication conditions: None, Water, and K-Y jelly (KY; Johnson \& Johnson, New Brunswick, $\mathrm{NJ}, \mathrm{USA}$ ). We weighed the jelly and dipped the cuff into the jelly to standardize the lubrication condition. The amount of K-Y jelly used was $1.5 \mathrm{~g}$ for ID $5.0-\mathrm{mm}$ and $1.2 \mathrm{~g}$ for ID 4.0-mm tracheal tubes. As depicted in Fig. 1, we placed a gas sampling tube just above the cuff to measure oxygen concentration. We confirmed an air leak when an apparent elevation of $\mathrm{O}_{2}$ concentration was detected within 2 min after switching the inspiratory gas from air to pure oxygen. Oxygen concentration was measured with an anesthetic gas analyzer (M1019A Intelliview, Philips, Andover, MA, USA). The duration of the experiment for each condition was $10 \mathrm{~min}$; we waited during a 5-min stabilization period and then observed the $\mathrm{O}_{2}$ concentration for 5 min after changing the inspiratory gas.

We performed two series of measurements by testing 5 new 4.0-mm ID tracheal tubes and 10 new 5.0-mm ID tracheal tubes. During experiment (A), the cuff pressure (CP) was maintained at $20 \mathrm{cmH}_{2} \mathrm{O}$ while the PAWP was increased from 5 to $25 \mathrm{cmH}_{2} \mathrm{O}$ in increments of $5 \mathrm{cmH}_{2} \mathrm{O}$. We defined the leak airway pressure (LAWP) to be the lowest PAWP at which leakage was detected. When no leakage was detected, the highest PAWP tested was considered the LAWP. The airway pressure was based on the settings of the built-in ventilator of the Avance Carestation, and the $\mathrm{CP}$ was measured with a cuff manometer (VBM Medizintechnik GmbH, Sulz am Neckar, Germany) that was calibrated in advance.

During experiment (B), the PAWP was maintained at $25 \mathrm{cmH}_{2} \mathrm{O}$ while the $\mathrm{CP}$ was decreased from 35 to 15 $\mathrm{cmH}_{2} \mathrm{O}$ in decrements of $5 \mathrm{cmH}_{2} \mathrm{O}$. We defined the leak $\mathrm{CP}$ (LCP) to be the highest $\mathrm{CP}$ at which leakage was detected. When leakage was not detected, the lowest $\mathrm{CP}$ studied was considered the LCP. On the basis of the above definitions, improvement of the air-sealing performance will result in a higher LAWP and a lower LCP. We compared the incidence of air leakage between the three different treatment groups by Fisher's exact test and compared LAWP and LCP between the treatment groups by Kruskal-Wallis test and Dunn's multiple comparison test. A $p$ value of 0.05 was considered to indicate statistical significance.

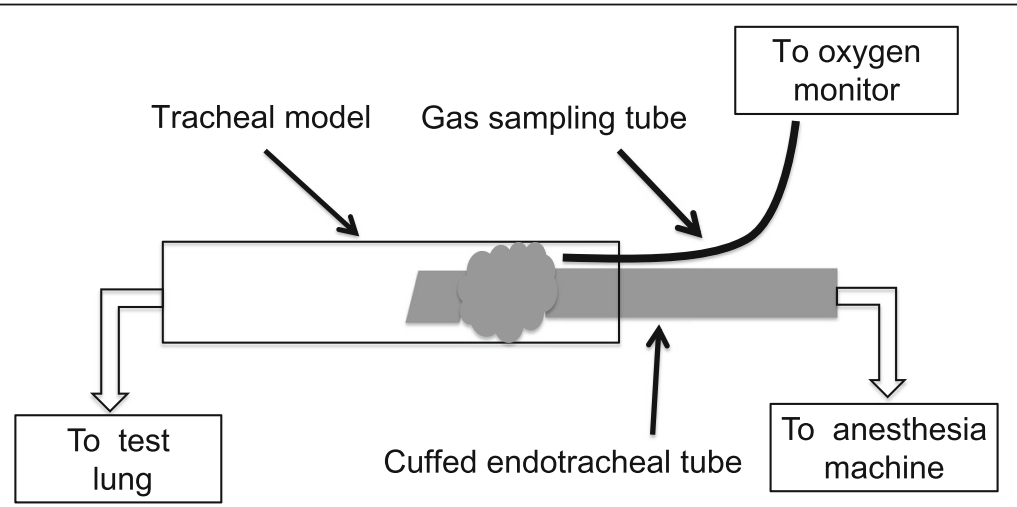

Fig. 1 Experimental setup for the in vitro assessment of air leakageA tracheal model was intubated with a pediatric cuffed endotracheal tube that was connected to a test lung. An anesthesia machine was connected to the endotracheal tube to ventilate the test lung. We placed a gas sampling tube just above the cuff to confirm air leakage by detecting an increase in oxygen concentration after changing the inspiratory gas from air to oxygen. 


\section{Results}

The incidences of air leakage during experiments (A) and (B) are shown in Tables 1,2. We detected air leakage in most of the tubes in the None and Water groups in both experiments. The incidence of leakage in the KY group was significantly lower than that in the other two groups for all conditions in experiment A using tracheal tubes with IDs of both 4.0 and $5.0 \mathrm{~mm}$. For experiment $\mathrm{B}$, the $\mathrm{KY}$ group showed a significantly lower incidence of leakage than the other two groups in most of the conditions for ID $4.0 \mathrm{~mm}$ and in all conditions for ID $5.0 \mathrm{~mm}$. The difference did not reach statistical significance in one of the conditions for ID $4.0 \mathrm{~mm}$.

As shown in Table 3, for both ID $4.0 \mathrm{~mm}$ and $5.0 \mathrm{~mm}$, the KY group showed significantly higher LAWP and significantly lower LCP compared with the other two groups. There was no significant difference in air-sealing performance between the None and Water groups.

\section{Discussion}

Lubrication with K-Y jelly improved the air-sealing performance of the pediatric cuffed tracheal tubes with ID 4.0 and $5.0 \mathrm{~mm}$ in our model experiment. Lubrication of the cylindrical shaped PVC cuff with K-Y jelly significantly lowered the CP needed to prevent air leakage compared with the non-treated and water-treated conditions. The application of water had no effect on the air-sealing properties compared with non-treated condition.

The outer diameters of the studied tracheal tubes with ID 4.0 and $5.0 \mathrm{~mm}$ were 5.6 and $6.7 \mathrm{~mm}$, and the diameters of their cuffs reached $13 \mathrm{~mm}$ and $16 \mathrm{~mm}$ at an inflation pressure of $20 \mathrm{cmH}_{2} \mathrm{O}$, respectively. Therefore, when we inflated the cylindrical shaped PVC cuff in the tracheal models with the diameters of 9 and $12 \mathrm{~mm}$, we observed longitudinal folds formed on the cuff surface, as we predicted. We also observed that KY jelly partially

Table 1 The incidence of air leakage in experiment A

\begin{tabular}{|c|c|c|c|c|c|c|}
\hline \multirow[b]{2}{*}{ Tube size } & \multirow[b]{2}{*}{ Lubrication } & \multicolumn{5}{|c|}{ Peak airway pressure $\left(\mathrm{cmH}_{2} \mathrm{O}\right)$} \\
\hline & & 5 & 10 & 15 & 20 & 25 \\
\hline \multirow[t]{4}{*}{$4.0 \mathrm{~mm}$} & None & $5 / 5$ & $5 / 5$ & $5 / 5$ & $5 / 5$ & $5 / 5$ \\
\hline & Water & $3 / 5$ & $5 / 5$ & $5 / 5$ & $5 / 5$ & $5 / 5$ \\
\hline & $\mathrm{K}-\mathrm{Y}$ jelly & $0 / 5$ & $0 / 5$ & $0 / 5$ & $0 / 5$ & $1 / 5$ \\
\hline & $P$ value & 0.009 & $<0.001$ & $<0.001$ & $<0.001$ & 0.011 \\
\hline \multirow[t]{4}{*}{$5.0 \mathrm{~mm}$} & None & $10 / 10$ & $10 / 10$ & $10 / 10$ & $10 / 10$ & $10 / 10$ \\
\hline & Water & $10 / 10$ & $10 / 10$ & $10 / 10$ & $10 / 10$ & $10 / 10$ \\
\hline & K-Y jelly & $1 / 10$ & $1 / 10$ & $2 / 10$ & $3 / 10$ & $3 / 10$ \\
\hline & $P$ value & $<0.001$ & $<0.001$ & $<0.001$ & $<0.001$ & $<0.001$ \\
\hline
\end{tabular}

The cuff pressure was maintained at $20 \mathrm{cmH}_{2} \mathrm{O}$ while the peak airway pressure was varied from 5 to $25 \mathrm{cmH}_{2} \mathrm{O}$ in increments of $5 \mathrm{cmH}_{2} \mathrm{O}$
Table 2 The incidence of air leakage in experiment B

\begin{tabular}{lllllll}
\hline \multirow{2}{*}{ Tube size } & & \multicolumn{6}{l}{ Cuff pressure $\left(\mathrm{CmH}_{2} \mathrm{O}\right)$} \\
\cline { 2 - 7 } & Lubrication & 15 & 20 & 25 & 30 & 35 \\
\hline $4.0 \mathrm{~mm}$ & None & $5 / 5$ & $5 / 5$ & $5 / 5$ & $5 / 5$ & $5 / 5$ \\
& Water & $4 / 5$ & $4 / 5$ & $4 / 5$ & $4 / 5$ & $4 / 5$ \\
& K-Y jelly & $1 / 5$ & $0 / 5$ & $0 / 5$ & $0 / 5$ & $0 / 5$ \\
& $P$ value & 0.051 & 0.006 & 0.006 & 0.006 & 0.006 \\
$5.0 \mathrm{~mm}$ & None & $10 / 10$ & $10 / 10$ & $10 / 10$ & $10 / 10$ & $10 / 10$ \\
& Water & $9 / 10$ & $9 / 10$ & $9 / 10$ & $9 / 10$ & $9 / 10$ \\
& K-Y jelly & $2 / 10$ & $1 / 10$ & $1 / 10$ & $1 / 10$ & $1 / 10$ \\
& $P$ value & $<0.001$ & $<0.001$ & $<0.001$ & $<0.001$ & $<0.001$ \\
\hline
\end{tabular}

The peak airway pressure was maintained at $25 \mathrm{cmH}_{2} \mathrm{O}$ while the cuff pressure was varied from 35 to $15 \mathrm{cmH}_{2} \mathrm{O}$ in decrements of $5 \mathrm{cmH}_{2} \mathrm{O}$

filled the space between the cuff surface and the wall of the model trachea. It is rational to assume that K-Y jelly prevents both air and liquid leakage through the channels formed by these longitudinal folds irrespective of differences in physical and rheological conditions. According to an earlier report, lubrication with K-Y jelly completely prevented liquid leakage in a model study using adult tracheal tubes with a conventional PVC cuff [4]; however, prevention of air leakage by K-Y jelly was incomplete in our study. These differences in the effects of lubrication may be explained by differences in various conditions between the two studies, such as brands of tracheal tubes used, the viscosity of air and water, and the pressure gradient inducing leakage. Our results may also suggest that KY jelly may not be optimal for the prevention of air leakage. It is likely that KY jelly is ineffective when large longitudinal folds are formed and that the effects of the lubricant last only for a short time. We should take these problems into account and consider other methods for preventing air leakage such as continuous control of CP in situations requiring long periods of ventilation.

Table 3 Leak airway pressure and leak cuff pressure in three different lubrication conditions

\begin{tabular}{lllll}
\hline \multirow{2}{*}{ Tube size } & Pressures & \multicolumn{3}{l}{ Lubrication } \\
\cline { 3 - 5 } & None & Water & K-Y jelly \\
\hline $4.0 \mathrm{~mm}$ & $\operatorname{LAWP}\left(\mathrm{cmH}_{2} \mathrm{O}\right)$ & $5(5)$ & $5(5)$ & $25(5-25)^{* *}, \ldots$ \\
& $\operatorname{LCP}\left(\mathrm{cmH}_{2} \mathrm{O}\right)$ & $35(35)$ & $35(15-35)$ & $15(15)^{* * \#}$, \\
$5.0 \mathrm{~mm}$ & $\operatorname{LAWP}\left(\mathrm{cmH}_{2} \mathrm{O}\right)$ & $5(5)$ & $5(5)$ & $25(15-25)^{* * * \#,}$, \\
& $\operatorname{LCP}\left(\mathrm{cmH}_{2} \mathrm{O}\right)$ & $35(35)$ & $35(15-35)$ & $15(15-35)^{* * * \#,}$, \\
\hline
\end{tabular}

LAWP: leak airway pressure, defined as the lowest peak airway pressure at which air leakage was detected. LCP: leak cuff pressure, defined as the highest cuff pressure at which air leakage was detected. When leakage was not detected, the highest peak airway pressure or the lowest cuff pressure studied was defined as LAWP or LCP, respectively

The values are reported as median and (range). $N=5$ for the experiments with ID $40 \mathrm{~mm}$ and $N=10$ for those with ID $5.0 \mathrm{~mm}$

${ }^{*} p<0.05$ vs. None group. ${ }^{* *} p<0.01$ vs. None group. ${ }^{* * *} p<0.001$ vs. None group. \#p $<0.05$ vs. Water group. \#\#p $<0.01$ vs. Water group. \#\#\# $<0.001$ vs, Water group 
We chose the fixed $\mathrm{CP}$ of $20 \mathrm{cmH}_{2} \mathrm{O}$ for experiment A. For adult patients, the safe range of the $\mathrm{CP}$ is variously considered to be 20 to $30 \mathrm{cmH}_{2} \mathrm{O}$ or 22 to 32 $\mathrm{cmH}_{2} \mathrm{O}$. [14, 15] The safe CP for pediatric patients is assumed to be lower than these values because of the assumed lower perfusion pressure in the tracheal wall, but it is uncertain. Earlier studies showed that cuffed endotracheal tubes resulted in comparable postextubation airway morbidity as uncuffed tubes when the $\mathrm{CP}$ was limited to $25 \mathrm{mmHg}$ in young children ranging in age from 0 to 8 years (mean, 3.3 years) and to 20 $\mathrm{cmH}_{2} \mathrm{O}$ in pediatric patients ranging in age from 0 to 5 years (median, 1.9 years). [16, 17] Therefore, we considered that $20 \mathrm{cmH}_{2} \mathrm{O}$ would be in the safe range for children in the trachea simulated in our study.

We chose the fixed PAWP of $25 \mathrm{cmH}_{2} \mathrm{O}$ for experiment $\mathrm{B}$ because we assumed that a PAWP of $25 \mathrm{cmH}_{2} \mathrm{O}$ is the upper limit encountered in clinical practice. It is common to confirm air leakage around a tracheal tube by manually applying positive airway pressure of $20-30$ $\mathrm{cmH}_{2} \mathrm{O}$ in pediatric anesthesia practice. [18] We consider that the condition of no air leakage at $25 \mathrm{cmH}_{2} \mathrm{O}$ PAWP would be safe as long as the baseline CP is in the safe range when tracheal tubes with large-volume cuffs are used. Therefore, we chose $25 \mathrm{cmH}_{2} \mathrm{O}$ as the maximum PAWP in this study. We also demonstrated that $\mathrm{K}-\mathrm{Y}$ jelly improved air-sealing performance at the $\mathrm{CP}$ of $15 \mathrm{cmH}_{2} \mathrm{O}$ in experiment $\mathrm{B}$ and at the lower PAWP in experiment A (Tables 1, 2).

Good air sealing provides several benefits in pediatric patients. These include effective ventilation, enhanced reliability of end-tidal gas monitoring and measurements of pulmonary mechanics, diminished contamination of the environment, less waste of inhalation anesthetics, and allowance of the use of low-flow anesthesia. $[16,17]$ Therefore, we think that there is an increasing need for safe cuffed endotracheal tubes with good air sealing for pediatric patients as cost concerns regarding the consumption of inhalation anesthetics increase. The Microcuff endotracheal tube seems to meet this need perfectly because it offers very good sealing to prevent air and liquid leakage at a very low $\mathrm{CP}$ that avoids stress on the tracheal wall. $[1,6,19]$ However, a drawback of this product is its high price. Our results suggest that lubrication with K-Y jelly would improve the air-sealing performance of pediatric tracheal tubes with a conventional PVC cuff and render these inexpensive tubes safe in providing a good air seal.

There are several limitations in our study. First, this study was performed with a tracheal model. The effectiveness of lubrication may be affected by various properties of the human trachea, such as the presence of humidity and airway secretions, the elasticity of the tracheal wall, and the irregular surface of the tracheal mucosa. Our findings need to be verified in clinical settings. Furthermore, the duration of the improvement in air-sealing performance in vivo should also be examined. A clinical study demonstrated that preventive effects of lubrication with KY jelly on liquid leaks lasted about $24 \mathrm{~h}$ in adult patients intubated with cuffed tracheostomy tubes. [3] To our knowledge, however, no study has investigated air leakage. Second, we only used two sizes of tracheal tube sized appropriately for older children. Further studies are needed to clarify whether our results will hold in other conditions such as simulating younger patients and using different tracheal tubes. Third, we did not evaluate the magnitudes of leakage because of the limited accuracy of the flow and volume measurements in our experiments, and this obscured the significance of the leakage observed. Finally, risks and benefits of applying lubricants need to be evaluated in various patient age groups as it has been shown that excess lubrication might obstruct the distal opening of the tracheal tube in infants. [20]

\section{Conclusions}

Lubrication with K-Y jelly improved the air-sealing performance of a pediatric endotracheal tube with a cylindrical shaped PVC cuff in our model experiments. Lubrication with $\mathrm{K}-\mathrm{Y}$ jelly but not water significantly lowered the $\mathrm{CP}$ needed to prevent air leakage. Future clinical studies are warranted to verify our findings and to evaluate the safety of using lubricants in various patient age groups.

\section{Abbreviations}

CP: Cuff pressure; CTT: Cuffed tracheal tube; ID: Internal diameter; LAWP: Leak airway pressure; LCP: Leak cuff pressure; PAWP: Peak airway pressure; PVC: Polyvinyl chloride

\section{Acknowledgements}

The authors thank to Tetsuya Miyaji, BS, chief medical engineer, for his technical assistance.

\section{Funding}

No funding was obtained for this study.

\section{Availability of data and materials \\ The datasets analyzed during the current study available from the} corresponding author on reasonable request.

\section{Authors' contributions}

H.N. collected and analyzed the data and wrote the manuscript draft. Y.U. helped with study design and interpretation of the data. G.H. and K.M. helped to collect and analyze the data. T.A. conceived the idea, designed the study, interpreted the data, and rewrote the manuscript. All authors read and approved the final manuscript.

Ethics approval and consent to participate

No patients or biological samples were included in this study. Therefore, ethical approval was not required.

Competing interests

The authors have no conflicts of interest to declare. 


\section{Publisher's Note}

Springer Nature remains neutral with regard to jurisdictional claims in published maps and institutional affiliations.

\section{Author details}

${ }^{1}$ Department of Anesthesiology, Mizonokuchi Hospital, Teikyo University School of Medicine, 3-8-3 Mizonokuchi, Takatsu-ku, Kawasaki 213-8507, Japan. ${ }^{2}$ Department of Anesthesiology, Saitama Medical University International Medical Center, 1397-1 Yamane, Hidaka City, Saitama 350-1298, Japan

Received: 9 October 2016 Accepted: 27 August 2017

\section{Published online: 19 September 2017}

\section{References}

1. Dullenkopf A, Schmitz A, Gerber AC, Weiss M. Tracheal sealing characteristics of pediatric cuffed tracheal tubes. Paediatr Anaesth. 2004; 14(10):825-30.

2. Madjdpour C, Mauch J, Dave MH, Spielmann N, Weiss M. Comparison of airsealing characteristics of tapered- vs. cylindrical-shaped high-volume, lowpressure tube cuffs. Acta Anaesthesiol Scand. 2012;56(2):230-5.

3. Blunt MC, Young PJ, Patil A, Haddock A. Gel lubrication of the tracheal tube cuff reduces pulmonary aspiration. Anesthesiology. 2001;95(2):377-81.

4. Dave MH, Koepfer N, Madjdpour C, Frotzler A, Weiss M. Tracheal fluid leakage in benchtop trials: comparison of static versus dynamic ventilation model with and without lubrication. J Anesth. 2010;24(2):247-52.

5. Sanjay PS, Miller SA, Corry PR, Russell GN, Pennefather SH. The effect of gel lubrication on cuff leakage of double lumen tubes during thoracic surgery. Anaesthesia. 2006;61(2):133-7.

6. Dullenkopf A, Gerber A, Weiss M. Fluid leakage past tracheal tube cuffs: evaluation of the new microcuff endotracheal tube. Intensive Care Med. 2003;29(10):1849-53.

7. Birket SE, Chu KK, Liu L, Houser GH, Diephuis BJ, Wilsterman EJ, Dierksen G, Mazur M, Shastry S, Li Y, et al. A functional anatomic defect of the cystic fibrosis airway. Am J Respir Crit Care Med. 2014;190(4):421-32

8. Habre W, Asztalos T, Sly PD, Petak F. Viscosity and density of common anaesthetic gases: implications for flow measurements. Br J Anaesth. 2001; 87(4):602-7.

9. Guyton DC, Barlow MR, Besselievre TR. Influence of airway pressure on minimum occlusive endotracheal tube cuff pressure. Crit Care Med. 1997; 25(1):91-4.

10. Young PJ, Rollinson M, Downward G, Henderson S. Leakage of fluid past the tracheal tube cuff in a benchtop model. Br J Anaesth. 1997;78(5):557-62.

11. Pfitzner J. Poiseuille and his law. Anaesthesia. 1976:31(2):273-5.

12. Bernet V, Dullenkopf A, Cannizzaro V, Stutz K, Weiss M. An in vitro study of the compliance of paediatric tracheal tube cuffs and tracheal wall pressure. Anaesthesia. 2006;61(10):978-83.

13. Griscom NT, Wohl ME. Dimensions of the growing trachea related to age and gender. AJR Am J Roentgenol. 1986;146(2):233-7.

14. Berry JM, Harvey S. Laryngoscopic orotracheal and nasotracheal intubation. In: Hagberg CA, editor. Benumof and Hagberg's Airway Management. 3rd edn. Saunders; 2012: p. 354.

15. Nseir $S$, Zerimech F, Fournier C, Lubret R, Ramon P, Durocher A, Balduyck M. Continuous control of tracheal cuff pressure and microaspiration of gastric contents in critically ill patients. Am J Respir Crit Care Med. 2011;184(9):1041-7

16. Khine HH, Corddry DH, Kettrick RG, Martin TM, McCloskey JJ, Rose JB, Theroux MC, Zagnoev M. Comparison of cuffed and uncuffed endotracheal tubes in young children during general anesthesia. Anesthesiology. 1997; 86(3):627-31. discussion 627A

17. Weiss M, Dullenkopf A, Fischer JE, Keller C, Gerber AC. Prospective randomized controlled multi-centre trial of cuffed or uncuffed endotracheal tubes in small children. Br J Anaesth. 2009;103(6):867-3.

18. Cote CJ. Pediatric anesthesia. In: Miller RD, editor. Miller's anesthesia. 8th ed. Philadelphia: Saunders; 2015. p. 2777-8.

19. Dullenkopf A, Gerber AC, Weiss M. Fit and seal characteristics of a new paediatric tracheal tube with high volume-low pressure polyurethane cuff. Acta Anaesthesiol Scand. 2005:49(2):232-7.

20. Tackley R. Transparent obstruction of RAE tube. Anaesthesia. 2001;56(3): 279-81.

\section{Submit your next manuscript to BioMed Central and we will help you at every step:}

- We accept pre-submission inquiries

- Our selector tool helps you to find the most relevant journal

- We provide round the clock customer support

- Convenient online submission

- Thorough peer review

- Inclusion in PubMed and all major indexing services

- Maximum visibility for your research

Submit your manuscript at www.biomedcentral.com/submit 